\title{
Time series of particulate and dissolved lipid classes during spring phytoplankton blooms in Bedford Basin, a marine inlet
}

\author{
Christopher C. Parrish \\ Department of Oceanography, Dalhousie University, Halifax, Nova Scotia B3H 4J1, Canada
}

\begin{abstract}
The Chromarod-Iatroscan TLC/FID system was used to measure lipid classes in the dissolved and particulate fractions of seawater samples taken during spring blooms in Bedford Basin, a small inlet in eastern Canada. Polar lipids were the major dissolved lipids present during the blooms. Dissolved lipid time series indicate decreased phytoplankton exudation and increased bacterial uptake of lipid classes at the time of the chlorophyll maximum. There is evidence to suggest algal uptake of dissolved phospholipids. This polar lipid class may be used by autotrophs as a source of $N$ and $P$ when inorganic nutrient levels are depleted. The energy-rich storage component, triglyceride, became the major particulate lipid class from the time of the chlorophyll maximum onwards. Other particulate lipid classes present after the chlorophyll maximum suggest that in addition to increased energy storage there was a greater degree of degradation of lipids and larger numbers of microheterotrophs.
\end{abstract}

\section{INTRODUCTION}

Large increases in numbers of microscopic plants are common in mid-latitude and high-latitude waters in spring. Enhanced sunlight, fewer storms and high nutrient levels expedite the conversion of $\mathrm{CO}_{2}$ to cellular material in the photic zone. As the plant bloom proceeds, inorganic nutrients become depleted. Under such conditions it is reasonable to assume that photoautotrophs favour the synthesis of compounds composed solely of $\mathrm{C}, \mathrm{H}$ and $\mathrm{O}$. Most lipids and carbohydrates are composed only of these 3 elements. Both these organic classes comprise essential energy storage and structural compounds. They differ in that lipids are considerably more reduced, and as a result, lipids can be oxidised to yield more than twice the amount of ATP per gram. Lipids are also more heterogeneous: they lack a well-defined monomeric unit.

Members of different lipid classes can be distinguished according to the types and proportions of elements present in the molecule. Lipid classes vary in the proportion of oxygen in the molecule, from hydrocarbons with none, to glycolipids which contain monosac- charide units. $\mathrm{P}$ and $\mathrm{N}$ are also common components of the more polar lipids, which include chlorophylls and phospholipids. Since there are considerable differences in both the structure and function of the various lipid classes (Parrish 1986), it would seem likely that the synthesis of individual classes would be favoured at different times during spring phytoplankton blooms.

To examine the patterns in lipid levels during blooms and specifically in response to varying nutrient concentrations, it is possible to use environments that are near 2 extremes in terms of complexity. By growing a single species of phytoplankton in a highly controlled environment it should be possible to examine the rate of production of intracellular and extracellular lipids as a function of the rate of supply of nutrients, provided all other variables are kept constant. This can be done with cage culture turbidostats (Parrish \& Wangersky 1987), which provide a means of maintaining a constant population density while preventing the accumulation of exudation products in the medium. Using this culture technique it was found that the rate of production of intracellular triglycerides in the diatom Phaeodactylum tricornutum increased with increasing nitrogen stress, while the rate of production 
of total lipids actually decreased. The rate of production of total dissolved lipids, however, did not change. What did change was the type of lipid compound that was released (Parrish \& Wangersky 1987).

In the present study of patterns in lipid levels a relatively complex environment has been chosen: Bedford Basin, Nova Scotia, Canada. Although this environment is vastly more complicated than any that might be experienced in a laboratory setting, it is still relatively simple by oceanographic standards: there is only a small freshwater input to Bedford Basin and there is a relatively limited exchange of seawater with the open ocean. The Bedford Basin spring bloom has previously been found to include Phaeodactylum tricornutum as the fifth most abundant species in surface waters (Platt et al. 1973) and thus it was anticipated that the laboratory experiments (Parrish \& Wangersky 1987) would be at least in part directly relevant to the Bedford Basin studies.

Until now, the only comprehensive field measurements of dissolved and particulate lipids during a spring phytoplankton bloom have been those of Kattner et al. $(1983 a, b)$. Their study, a detailed description of fatty acid moieties in North Sea samples, documents changes in the types of fatty acids that occur during a bloom. They also measured dissolved acyl $(\mathrm{R}-\mathrm{C}=\mathrm{O})$ lipid classes in surface waters during the bloom period (Kattner et al. 1983b). They found that free (not esterified) fatty acids were the major dissolved acyl lipids present, and observed a maximum concentration of free as well as total fatty acids just after the period of maximum phytoplankton growth. Morris et al. (1983) also recorded a peak in total dissolved lipids just after the chlorophyll a maxima in an ecosystem bag. The present study is the first to document changes in concentrations of the complete range of dissolved and particulate lipid classes during a phytoplankton bloom.

\section{METHODS}

To examine distributions of marine lipid classes during spring phytoplankton blooms, samples were collected in Bedford Bay, Bedford Basin and Halifax Harbour, Nova Scotia (Fig. 1). Most of the samples were collected in Bedford Basin, a small $\left(17 \mathrm{~km}^{2}\right)$ marine inlet connected via Halifax Harbour to the Atlantic. Halifax Harbour is generally shallower than Bedford Basin and there is only limited seawater exchange between the two. This exchange occurs through The Narrows, which provides an effective sill depth of $20 \mathrm{~m}$ and a minimum total width of $375 \mathrm{~m}$. The major freshwater input to Bedford Basin is from a single small river, the Sackville River, via Bedford Bay. The sampling station used in Bedford Basin was located at its

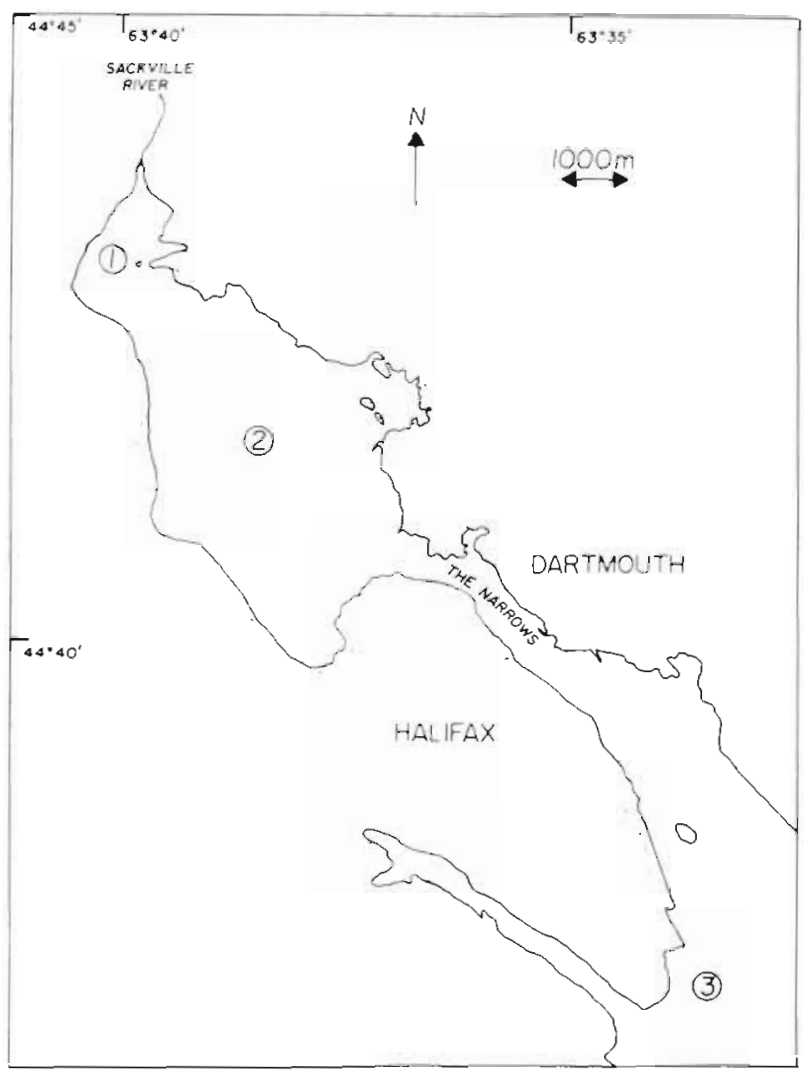

Fig. 1. Sampling stations in (1) Bedford Bay, $15 \mathrm{~m}$ of water; (2) Bedford Basin, $70 \mathrm{~m}$ of water; and (3) Halifax Harbour, $25 \mathrm{~m}$ of water

centre in $70 \mathrm{~m}$ of water. This station has been occupied for other studies of phytoplankton blooms (Platt et al. 1973, Conover 1975, Conover \& Mayzaud 1984). The present study is concerned with seawater samples taken during the spring blooms of 1982 and 1984; it concentrates on measurements that were common to both years.

Spring bloom 1982. Samples were collected for lipid analyses in the early afternoon every 2 to $3 \mathrm{~d}$ over a period of $27 \mathrm{~d}$ in March and April. Sampling was conducted from the M.V. Sigma T in the top $10 \mathrm{~m}$ of the water column at the centre of Bedford Basin (Fig. 1). Samples were trapped in a conventional 301 Niskin bottle at the bottom of the surface mixed layer as discerned from the temperature trace of a Guildline CSTD. The CSTD temperature profiles and the exact sampling depths are given by Lewis et al. (1984). On Julian Day 91 an additional sample was collected at $0.5 \mathrm{~m}$.

Once the water sample was on board it was transferred via silicone tubing to precleaned and samplerinsed $4 \mathrm{I}$ amber glass solvent bottles. In the laboratory the samples were swirled in the bottles and screened through a metal sieve (ca $250 \mu \mathrm{m}$ mesh) before filtering 
through precombusted Gelman A/E filters. For particulate lipid measurements, 1.75 l was normally filtered; usually $250 \mathrm{ml}$ was used for dissolved lipid measurements. All filtrations and extractions were done in triplicate or quadruplicate, and a total system blank was run for each set of extractions.

All extractions were performed with cold dichloromethane that had been freshly redistilled under purified nitrogen. Immediately before extracting, all glassware was rinsed with this $\mathrm{CH}_{2} \mathrm{Cl}_{2}$. Dissolved lipids were then extracted with a total of $40 \mathrm{ml}$ of $\mathrm{CH}_{2} \mathrm{Cl}_{2}$, particulate lipids with a total of $20 \mathrm{ml}$. All extractions were completed within $5 \mathrm{~h}$ of sampling; during this period exposure of samples and extracts to light, heat and oxygen was minimised.

Chromarod thin-layer chromatography and Iatroscan flame ionization detection were used to measure the lipid classes in the extracts. TLC/FID was performed with Chromarods SII and an Iatroscan MK III (Iatron Laboratories, Tokyo) using modifications of previously described procedures (Delmas et al. 1984, Parrish \& Ackman 1985), as detailed in Parrish (1986).

Lipid classes were separated on the silica gel coated Chromarods in a stepwise sequence with partial scanning between developments. Hexane-based solvent systems were used to separate neutral lipids and acetone and a dichloromethane-based solvent system to separate polar lipids. The separated classes were measured in the Iatroscan at a relatively high scan rate $\left(4.2 \mathrm{~mm} \mathrm{~s}^{-1}\right)$ and hydrogen flow rate $\left(173 \mathrm{ml} \mathrm{min}^{-1}\right)$ in order to maximise FID response. For the 1982 spring bloom samples the total analytical precision (CV) of both dissolved and particulate lipid class determinations was normally between 15 and $30 \%(n=4)$; blank levels were usually below $10 \%$.

Spring bloom 1984. The same station was occupied in 1984. Samples for lipid class measurements were taken around noon, once or twice a week. This 1984 study was part of a larger programme described in detail by Roy (1986). The present study is mainly concerned with particulate samples collected at $5 \mathrm{~m}$ from February to April in the centre of Bedford Basin. Further details concerning 1984 sampling stations are given by Parrish (1986).

The $5 \mathrm{~m}$ Bedford Basin samples provided the most comprehensive time-series of lipid measurements in 1984. These samples were collected in 51 Go-Flo bottles and processed for particulate lipid measurement as described for the 1982 spring bloom. Particulate organic carbon (POC) and nitrogen (PON) concentrations were also measured in these samples. POC and PON were determined after combustion in pure oxygen in a Perkin-Elmer CHN analyser (Model 240B). Carbon and nitrogen values were standardized using cyclohexanone-2:4-dinitro-phenylhydrazone (BDH).

\section{RESULTS AND DISCUSSION}

Diatom blooms were observed within the top $10 \mathrm{~m}$ of the water column at the centre of Bedford Basin in March of 1982 and 1984. The in situ fluorescence maximum usually coincided with the beginning of the pycnocline, which was almost always found within the top $10 \mathrm{~m}$ throughout both periods of study.

\section{2 spring bloom: general observations}

In 1982, water samples were taken from the bottom of the mixed layer: usually around $5 \mathrm{~m}$. The bloom observed during this month-long sampling period was dominated by representatives of the genus Melosira. The chlorophyll a data (Fig. 2a) suggest that this bloom was close to the classic concept of a spring bloom. The maximum observed chlorophyll value coincided with a period in which there was the sharpest decrease in nitrate (Fig. 2b). Nutrient levels then remained low for

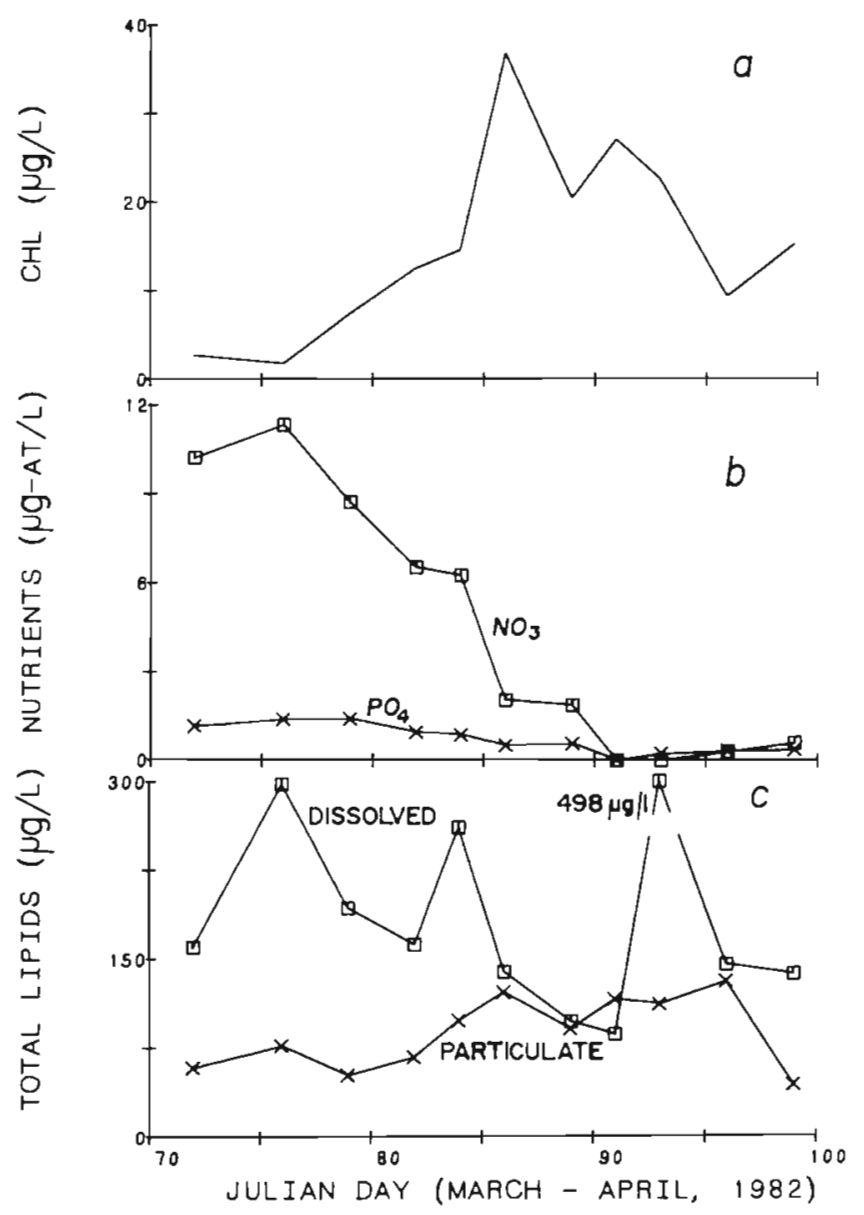

Fig. 2. Spring bloom 1982; chlorophyll, nutrient and total lipid concentrations at bottom of surface mixed layer in Bedford Basin. (a) Fluorometric chlorophyll a. (b) Nitrate and phosphate, (c) Total dissolved and total particulate lipid 
the next $2 w k$, and chlorophyll a concentrations generally declined. There was, however, a second chlorophyll peak observed during this period and the value from the last sampling day suggests that there might have been a third peak in this series.

Two of the peaks in total particulate lipid concentrations (Fig. 2c) coincided with the chlorophyll a maxima (Fig. 2a), but the highest total particulate lipid value occurred $10 \mathrm{~d}$ after the highest chlorophyll value. This pattern is almost identical to that observed by Morris et al. (1983) in $3 \mathrm{~m}$ samples from a spring diatom bloom in an enclosed ecosystem bag. The pattern for total dissolved lipids (Fig. 2c) is also similar to that at $3 \mathrm{~m}$ in the ecosystem bag (Morris et al. 1983). Lowest dissolved lipid concentrations occurred near the time of the chlorophyll maxima, and highest values were measured before and after this period. Kattner et al. (1983b) also measured a trough in total dissolved fatty acid concentrations coincident with the maximum in phytoplankton growth during a North Sea bloom. These decreases in dissolved lipid concentrations could be the result of a greatly decreased rate of exudation on a per algal cell basis and/or a greatly increased rate of uptake by bacteria and possibly even by phytoplankton.

\section{Particulate and dissolved lipid classes, 1982}

Table 1 gives the mean composition of dissolved and particulate lipids during the 1982 bloom. From the $95 \%$ confidence intervals it can be seen that concentrations of the dissolved lipid classes were more variable than those of the same class in the particulate fraction. The mean concentration, however, was usually quite similar for the 2 fractions.
There were 2 exceptions to this general similarity. Concentrations of ALC and AMPL (abbreviations explained in Table 1) were consistently higher in the dissolved fraction. It is not known which compounds are present in these 2 classes, but it is likely that phytol and monoglycerides are among the major components (Parrish 1986). These would be expected to occur during bloom periods as a result of hydrolysis of chlorophylls and acyl lipids.

ALC and AMPL together with PL were, on average, the major components of the dissolved lipids. This is in contrast to the results of Kattner et al. (1983b) who found FFA and TG to be the major contributors during a spring bloom in the North Sea. The data in Table 1 and those given by Kattner et al. (1983b) are not directly comparable since Kattner et al. measured only acyl lipids and only in terms of carbon. However, by using representative compounds (Parrish 1986), it is possible to estimate a total weight for each acyl lipid class. Also, with the knowledge that TLC/FID lipid class measurements give values close to 'true' gravimetric values (Fraser et al. 1985, Parrish 1986), the values in Table 1 can be used to estimate the relative proportions of the acyl lipid classes in Bedford Basin. With these corrections, FFA still accounts for over $40 \%$ by weight of acyl lipids during the North Sea bloom, while remaining under $10 \%$ during the Bedford Basin bloom.

Correspondence of the particulate lipid values (Table 1) with literature values (Morris et al. 1983) is closer than for the dissolved lipids. HC was not included in percent composition calculations by Morris et al. (1983), and so the values in Table 1 have to be adjusted slightly to be comparable. TG, an important storage class in phytoplankton, was a major contributor in both studies. TG also comprised a signifi-

Table 1. Dissolved and particulate lipid class concentrations ( $\left.\mathrm{g} \mathrm{l}^{-1}\right)$ and proportions $(\%)$ at the bottom of the surface mixed layer during the 1982 Bedford Basin spring bloom. Values are mean TLC/FID measurements for the 11 sampling days $\pm 95 \%$ confidence intervals

\begin{tabular}{|c|c|c|c|c|c|}
\hline \multirow[t]{2}{*}{ Class } & \multirow[t]{2}{*}{ Abbreviation } & \multicolumn{2}{|c|}{ Dissolved lipids } & \multicolumn{2}{|c|}{ Particulate lipids } \\
\hline & & $\mu g \mathrm{l}^{-1}$ & $\%$ & $\mu g 1^{-1}$ & $\%$ \\
\hline Aliphatic hydrocarbon & $\mathrm{HC}$ & $7.8 \pm 3.4$ & $4 \pm 2$ & $9.5 \pm 3.2$ & $12 \pm 5$ \\
\hline Wax ester/sterol ester & $W E^{\circ}$ & $4.1 \pm 2.4$ & $3 \pm 2$ & $1.9 \pm 0.9$ & $2 \pm 1$ \\
\hline Triglyceride & TG & $14 \pm 11$ & $7 \pm 4$ & $23 \pm 9$ & $26 \pm 6$ \\
\hline Free fatty acid & FFA & $13 \pm 4$ & $7 \pm 2$ & $11 \pm 5$ & $12 \pm 4$ \\
\hline Free aliphatic alcohol & $\mathrm{ALC}^{\mathrm{b}}$ & $19 \pm 9$ & $11 \pm 6$ & $5.2 \pm 2.5$ & $6 \pm 2$ \\
\hline Free sterol & $\mathrm{ST}^{\mathrm{c}}$ & $9.6 \pm 6.7$ & $4 \pm 1$ & $5.1 \pm 2.4$ & $6 \pm 2$ \\
\hline Acetone-mobile polar lipids & $A M P L^{d}$ & $88 \pm 6$ & $46 \pm 10$ & $24 \pm 5$ & $28 \pm 5$ \\
\hline Phospholipid & PL & $39 \pm 36$ & $17 \pm 8$ & $6.9 \pm 3.1$ & $8 \pm 3$ \\
\hline \multicolumn{6}{|c|}{$\begin{array}{l}\text { A small peak adjacent to the WE peak with the } R_{f} \text { of methyl esters (Parrish \& Ackman 1983) was detected in } \\
\text { Often composed of } 2 \text { peaks } \\
\text { A small peak adjacent to the ST peak with the } R_{f} \text { of diglycerides was detected in a few particulate samples } \\
\text { This ILC/FID lipid class may contain monoglycerides, glycolipids, and chlorophylls }\end{array}$} \\
\hline
\end{tabular}


cantly larger proportion of particulate lipids than of dissolved lipids (Table 1). AMPL, which is undoubtedly equivalent to 'monoglycerides' in the ecosystem bag study (Morris et al. 1983), was also an important contributor. The particulate AMPL band on the Chromarods clearly contains chlorophyll a, and a comparison of particulate AMPL concentrations with fluorometric chlorophyll a concentrations suggests that chlorophylls account for about $2 / 3$ of this band.

Fig. 3 shows the classes with the clearest trends in both the particulate and dissolved fractions in 1982. These time series suggest an approximately reciprocal relation for class concentrations in the 2 fractions of seawater. The dissimilarity in the patterns for the dissolved and particulate lipid classes is emphasized by the fact that there was only one significant correlation between dissolved and particulate measurements of the same class (Table 2).

Particulate lipid classes contrast with their dissolved counterparts by having at least one peak coincident with the chlorophyll maxima (Julian Days 86 and 91), while the dissolved classes have their lowest values around this time (Fig. 3). This pattern of low values extends to time series of dissolved FFA, ST and AMPL. Kattner et al. (1983b) also recorded low dissolved TG and FFA concentrations at the time of maximum phytoplankton growth. Both these classes contain energyrich compounds that may be used by bacteria which are presumably also highly active at this time during blooms.

The concentrations of many dissolved lipid classes increased significantly after the low values associated with the chlorophyll maxima. The highest ALC, ST, AMPL, and PL concentrations for the 1982 bloom were

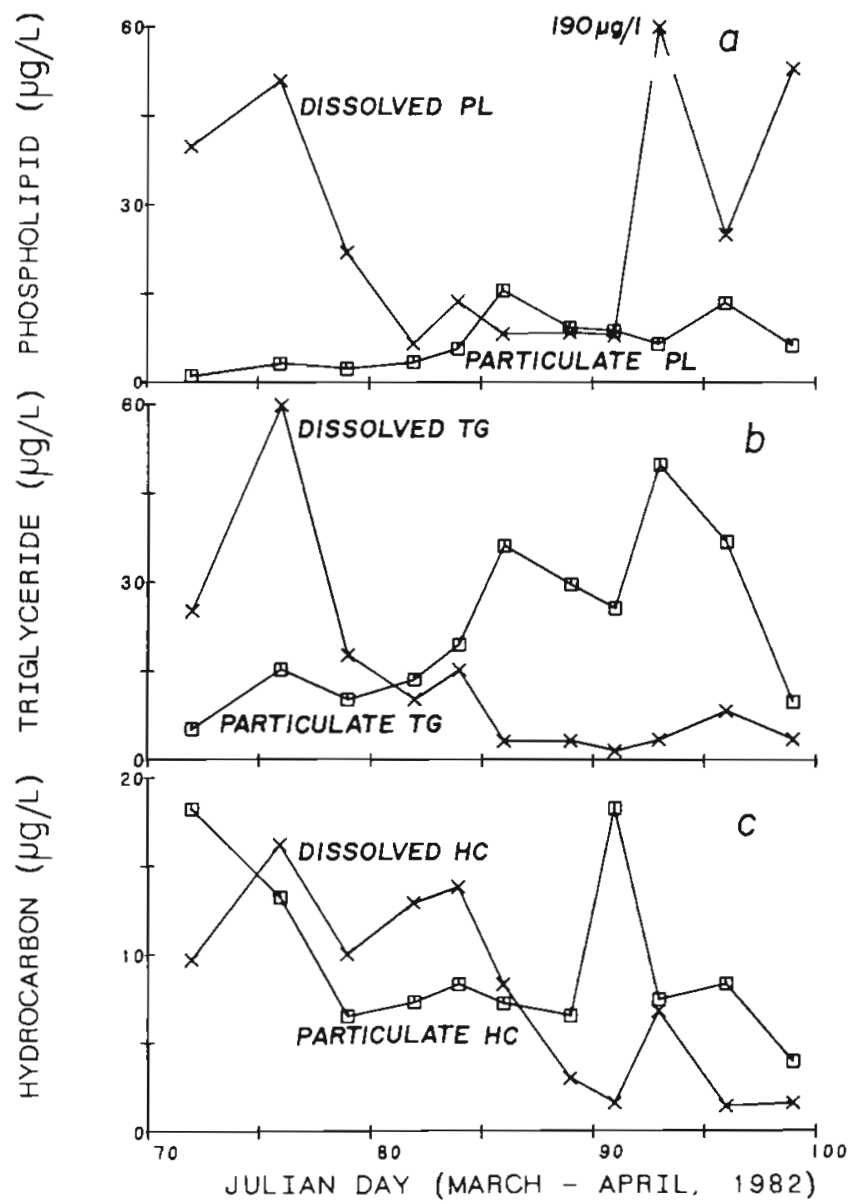

Fig. 3. Spring bloom 1982; dissolved and particulate lipid class concentrations at bottom of surface mixed layer in Bedford Basin. (a) Dissolved and particulate phospholipid. (b) Dissolved and particulate triglyceride. (c) Dissolved and particulate hydracarbon

Table 2. Pearson product moment linear correlation coefficients for lipid class concentrations ( $\mu \mathrm{g}^{-1}$ ) during the 1982 spring bloom. Abbreviations explained in Table 1; prefixes ' $d$ ' and ' $p$ ': dissolved or particulate: 'TOT': sum of lipid classes

\begin{tabular}{|c|c|c|c|c|c|c|c|c|c|}
\hline & $\mathrm{CHL}$ & pTOT & $\mathrm{pHC}$ & pTG & $\mathrm{pFFA}$ & pALC & $\mathrm{pST}$ & pAMPL & $\mathrm{pPL}$ \\
\hline dTOT & $\therefore$ & - & - & - & - & - & - & - & - \\
\hline $\mathrm{pHC}$ & - & - & & - & - & - & - & - & - \\
\hline $\mathrm{dHC}$ & - & - & - & - & - & - & - & - & - \\
\hline pTG & 0.62 & 0.85 & - & & - & 0.82 & 0.78 & - & 0.71 \\
\hline dTG & -0.70 & - & - & - & - & - & - & - & - \\
\hline pFFA & - & 0.68 & - & - & & - & - & - & - \\
\hline $\mathrm{dFFA}$ & - & - & - & - & - & - & - & - & - \\
\hline pALC & - & 0.71 & - & 0.82 & - & & 0.79 & - & 0.64 \\
\hline dALC & - & - & - & 0.76 & - & 0.70 & 0.83 & - & - \\
\hline$p S T$ & - & 0.74 & - & 0.78 & - & 0.79 & & - & 0.71 \\
\hline $\mathrm{dST}$ & - & - & - & - & - & - & - & - & - \\
\hline pAMPL & - & 0.65 & - & - & - & - & - & & - \\
\hline dAMPL & - & - & - & - & - & - & - & - & - \\
\hline $\mathrm{pPL}$ & 0.72 & 0.79 & - & 0.71 & - & 0.64 & 0.71 & - & \\
\hline $\mathrm{dPL}$ & - & - & - & - & - & - & - & - & - \\
\hline
\end{tabular}


measured during the period of declining chlorophyll values. The wide range of chemical structures involved would suggest a non-specific source for these dissolved compounds. Cell lysis, either autolysis or mechanical rupture as a result of zooplankton grazing, could be at least partly the cause of such a large input of dissolved lipids to the water column.

Not all dissolved lipid classes had maximal or even high concentrations after the chlorophyll maxima. Dissolved TG and $\mathrm{HC}$ tended to decrease throughout the entire sampling period (Fig. 3b,c). This pattern contrasts with particulate TG, FFA, ALC, ST and PL which tended to increase through the times of the chlorophyll maxima as well as afterwards for at least a few days. Particulate $\mathrm{HC}$, however, shares some features with its dissolved counterpart: both had high values at the beginning of the sampling period and low values at the end (Fig. 3c). These results suggest similarities with observations made by Gordon et al. (1978) at the centre of Bedford Basin. These workers performed a temporal study of hydrocarbons using unfiltered water samples; their total $n$-alkane concentrations in March were among the highest observed during the year. These elevated levels were suggested to be the result of anthropogenic inputs (Gordon et al. 1978).

\section{4 spring bloom: general observations}

The $5 \mathrm{~m}$ sample depth used in 1984 was found to be within or close to haloclines and thermoclines detected with a Beckman RS5-3 electrodeless induction salinometer. The $5 \mathrm{~m}$ bottle sample was also found to be usually very close to the depth of the in situ fluorescence maximum. On one day, Julian Day 68, a very distinct in situ fluorescence maximum was observed at $3 \mathrm{~m}$, and so on that day the water sample was taken at that depth rather than at the usual depth. The 1984 bloom was different from that of 1982 in that it was dominated by Chaetoceros spp. and chlorophyll a values (Fig. 4a) did not reach the levels attained in 1982 (Fig. 2a). In 1984 maximum chlorophyll a and POC levels were observed at $3 \mathrm{~m}$ on Julian Day 68 (Fig. 4a,b). These levels were accompanied by the lowest measured nitrate and phosphate concentrations (Fig. 4c).

After Julian Day 68 there was a substantial increase in nutrients at $5 \mathrm{~m}$ (Fig. 4c). This was probably the result of increased runoff as well as mixing with deeper water. Five of the $7 \mathrm{~d}$ between Julian Days 70 and 76 were characterized by wind speeds above normal' for March (Environment Canada 1984) as well as above the mean for March 1984. On 2 consecutive days wind speeds were more than $50 \%$ higher than the mean for the month and their prevailing direction was

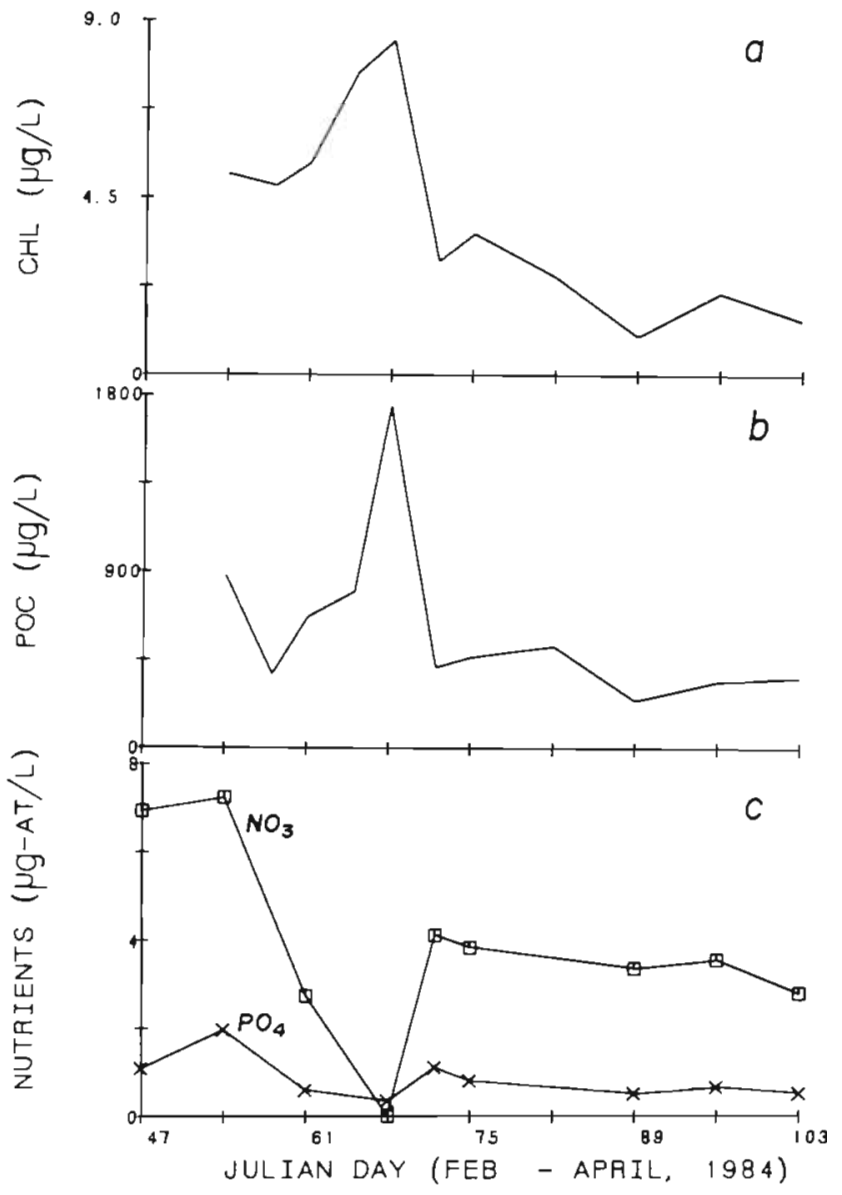

Fig. 4. Spring bloom 1984; chlorophyll, carbon and nutrient concentrations at $3 \mathrm{~m}$ and $5 \mathrm{~m}$ in Bedford Basin. Marks on the $\mathrm{x}$-axis are spaced $1 \mathrm{wk}$ apart. (a) Fluorometric chlorophyll a.

(b) Particulate organic carbon. (c) Nitrate and phosphate

along the longest dimension of the Basin. On these $2 \mathrm{~d}$ the Halifax-Dartmouth area received one third of the month's rainfall (Environment Canada 1984), and the end of the $7 \mathrm{~d}$ period was marked by high daily discharge from the Sackville River (Water Survey of Canada 1985). This discharge was in fact the highest measured during all of 1984 .

What is surprising about the data in Fig. 4 is that despite the partial recovery in nutrient levels and a long period of relative stability in the water column (Roy 1986, Parrish 1986) there was no major second bloom. Following the storm, chlorophyll $a$ and POC levels continued their downward trend, albeit more gradually.

Although there were distinct differences between the 1982 and 1984 blooms in both absolute concentrations and timing of peaks and troughs, there were also clear similarities. There was a steep increase in chlorophyll a levels in March of both years followed by an equally steep decrease and then 2 secondary increases in chlorophyll levels. Nutrients did not 
remain low after the first chlorophyll maximum in 1984, but nonetheless there are some indications of nutrient stress. $\mathrm{C}: \mathrm{N}$ atomic ratios as high as 7.2 were measured after Julian Day 68 at $5 \mathrm{~m}$. A value as high as 10.0 was measured at $1 \mathrm{~m}$ on Julian Day 75. Atomic ratios between 7 and 10 were also observed in surface waters by Conover (1975) during the late stages of Bedford Basin spring blooms when concentrations of various nitrogen-containing nutrients had become markedly reduced. High HPLC-measured chlorophyll $c$ : chlorophyll a ratios and carbon:chlorophyll a ratios may be further evidence for phytoplankton stress after Julian Day 68 in 1984 (Roy 1986). In addition to suboptimal nutrient conditions, surface-layer phytoplankton were possibly experiencing sub-optimal light conditions following Julian Day 68. In the $3 \mathrm{wk}$ after Julian Day 68, when chlorophyll levels generally declined, the average number of hours of 'bright sunshine' (Environment Canada 1984) per day was more than $2 \mathrm{~h}$ less than during the period of rapidly increasing chlorophyll concentrations (Julian Days 61 to 68). The 3 wk of lower light levels included 6 consecutive days of $0.0 \mathrm{~h}$ bright sunshine.

Concomitant with the differences in chlorophyll a and nutrient levels, differences were also observed in particulate lipid distributions in 1982 and 1984 (Fig. 3 $\& 5)$. However, given the dearth of available lipid class data from blooms and the complexity of the processes governing their distributions, it was felt that a detailed discussion of inter-annual variability should await further field measurements. The principal aim of this discussion is thus to examine similarities in lipid distributions during the bloom periods in order to make generalizations that should be applicable to other blooms.

As in the 1982 spring bloom, total particulate lipid levels were much higher following the chlorophyll maximum than before (Fig. 5a), but the effect was much more pronounced and much more prolonged. This may possibly be related to the presence of significant levels of nutrients during this period. Alternatively it may be related to the fact that sampling was terminated much sooner after the chlorophyll maximum in 1982 than in 1984.

Dissolved lipid classes were also extracted from $5 \mathrm{~m}$ samples but on only 5 occasions so the time series are not shown here. Some of these data can be found in Fig. 6 and in Parrish (1986). Samples of dissolved and particulate lipids were also taken from $1 \mathrm{~m}$, and again some of these data can be found in Fig. $6 \& 7$ and in Parrish (1986). In addition to sampling over a longer period and from more depths than in 1982, sampling in 1984 was not restricted to the central Bedford Basin station. On 2 occasions (Julian Days 72 and 103) measurements were made at 2 additional stations: one near

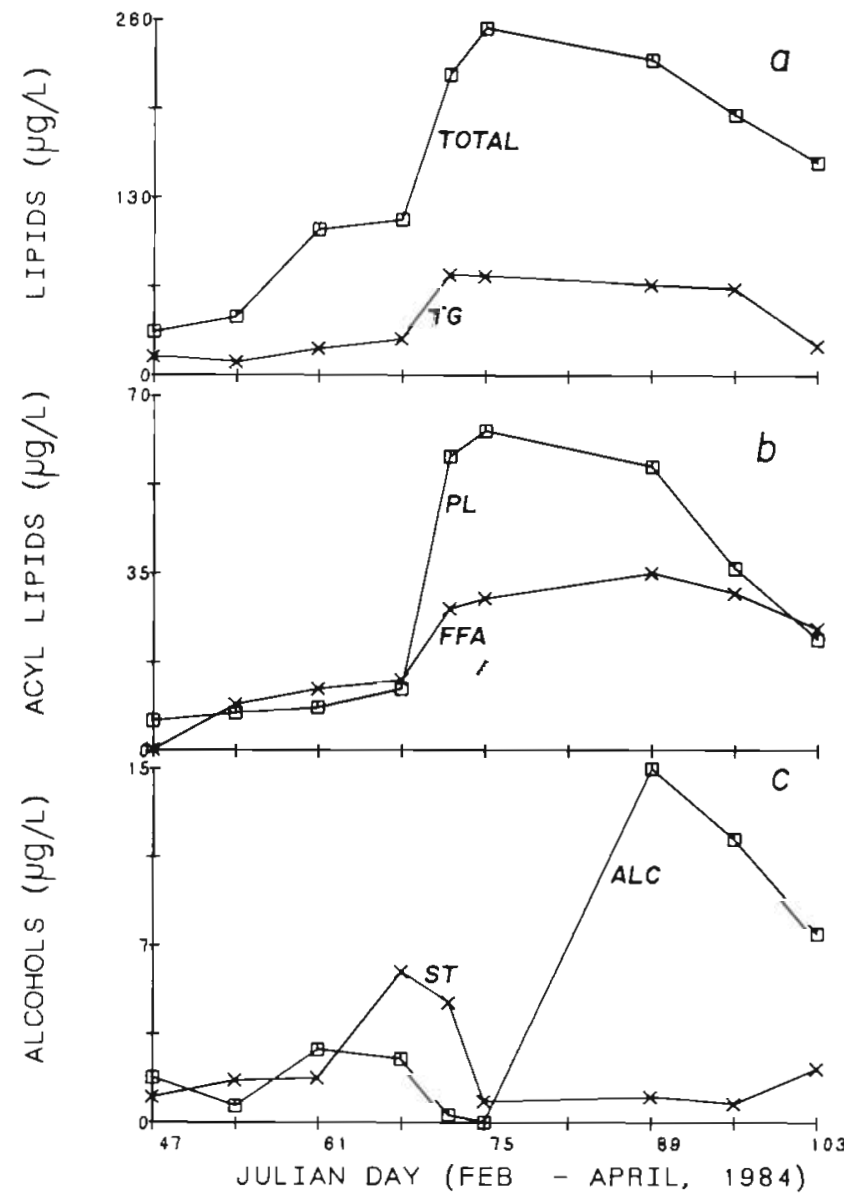

Fig. 5. Spring bloom 1984; particulate lipid concentrations at $3 \mathrm{~m}$ and $5 \mathrm{~m}$ in Bedford Basin. (a) Total particulate lipid and triglyceride. (b) Phospholipid and free fatty acid. (c) Free aliphatic alcohol and free sterol

the small freshwater input to the Basin, and the other on the seaward side of the Basin's narrow connection with the open ocean (Fig. 1). Both stations were $>3 \mathrm{~km}$ from the centre of Bedford Basin. They were sampled in an attempt to estimate the effects of mixing with water outside the basin on the interpretation of time series and profiles from the centre of Bedford Basin. There were, however, few consistent patterns either vertically or horizontally for the 3 stations. For most of the parameters measured, either there were no significant unidirectional gradients or else differences between the 3 stations at the same sampling depths were significantly smaller than differences between depths within each station. Except, perhaps, for hydrocarbon data (Fig. 6a), it can be seen that lipid data from the 2 additional stations fit well with the Bedford Basin data collected in 1982 and 1984 (Fig. 6\& 7).

Measurements of salinity and nitrate were a clear exception to the general similarity between the 3 stations. On Julian Day 103 there was a gradient of $3 \%$ from Bedford Bay to Halifax Harbour accompanied by a reverse gradient of about $1.5 \mu \mathrm{g}$-at $l^{-1}$ of nitrate. 


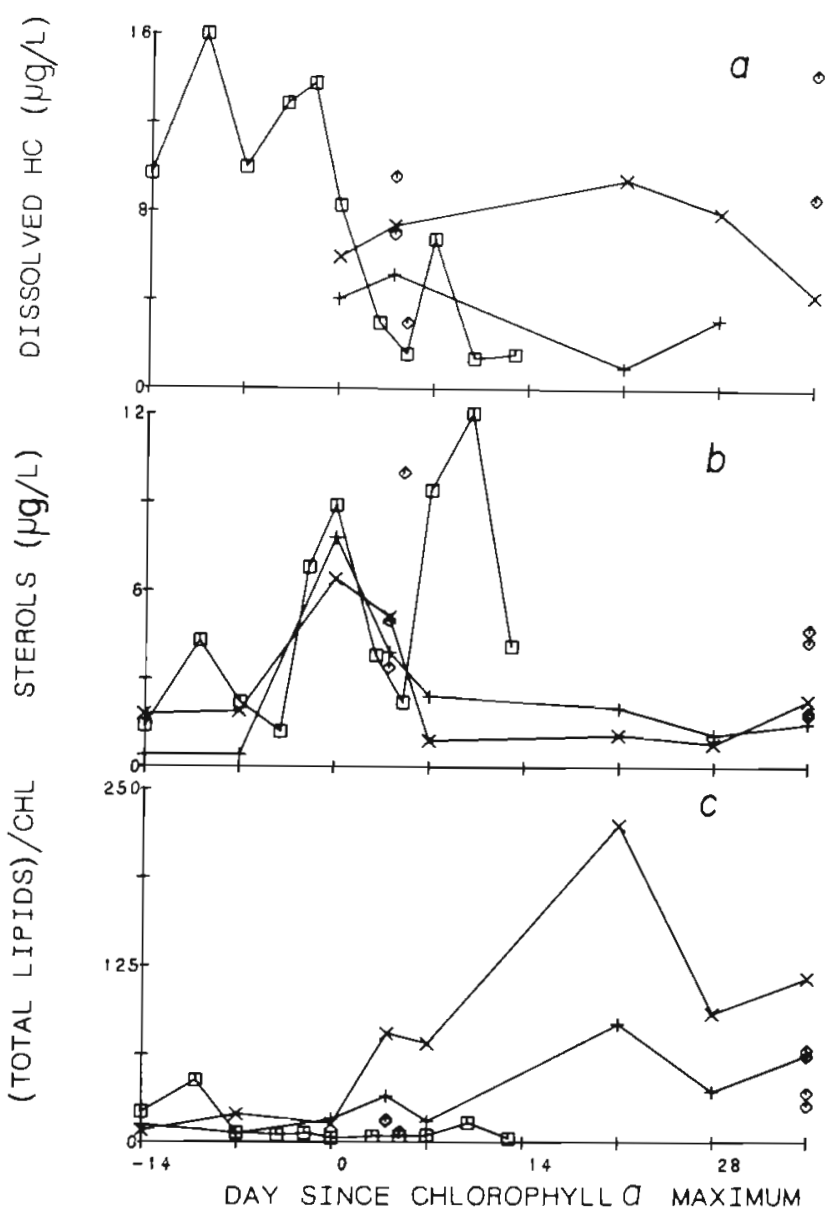

Fig. 6. Dissolved and particulate lipids from 2 blooms and 3 stations. Marks on the $x$-axis are spaced at weekly intervals from the 1982 and 1984 Bedford Basin chlorophyll a maxima. (D) Bedford Basin 1982 samples from bottom of surface mixed layer; (x) 1984 Bedford Basin $3 \mathrm{~m}$ and $5 \mathrm{~m}$ data; (+) 1984 Bedford Basin $1 \mathrm{~m}$ data; $(\diamond)$ remaining surface mixed layer depths and stations from both 1982 and 1984 spring blooms. (a) Dissolved hydrocarbon concentrations. (b) Particulate sterol concentrations. (c) Ratio of total particulate lipids to chlorophyll a

\section{Particulate lipid classes in Bediord Basin, 1984}

Triglyceride again became the major lipid class from the time of the chlorophyll maximum onwards (Fig. $5 \mathrm{a}$ ), and again the maximum in TG per unit chlorophyll or per unit carbon occurred some time after the chlorophyll maximum ( $3 \mathrm{wk}$ ). This has considerable implications for the quality (in terms of energy) of particulate material to grazers. It is interesting that the highest zooplankton activity measured by Conover \& Mayzaud (1984) during a spring bloom in Bedford Basin was after the chlorophyll maximum. The highest zooplankton ingestion rates in terms of particle volume or of organic carbon occurred from 4 to $18 \mathrm{~d}$ after the chlorophyll maximum in the top $5 \mathrm{~m}$ of the water

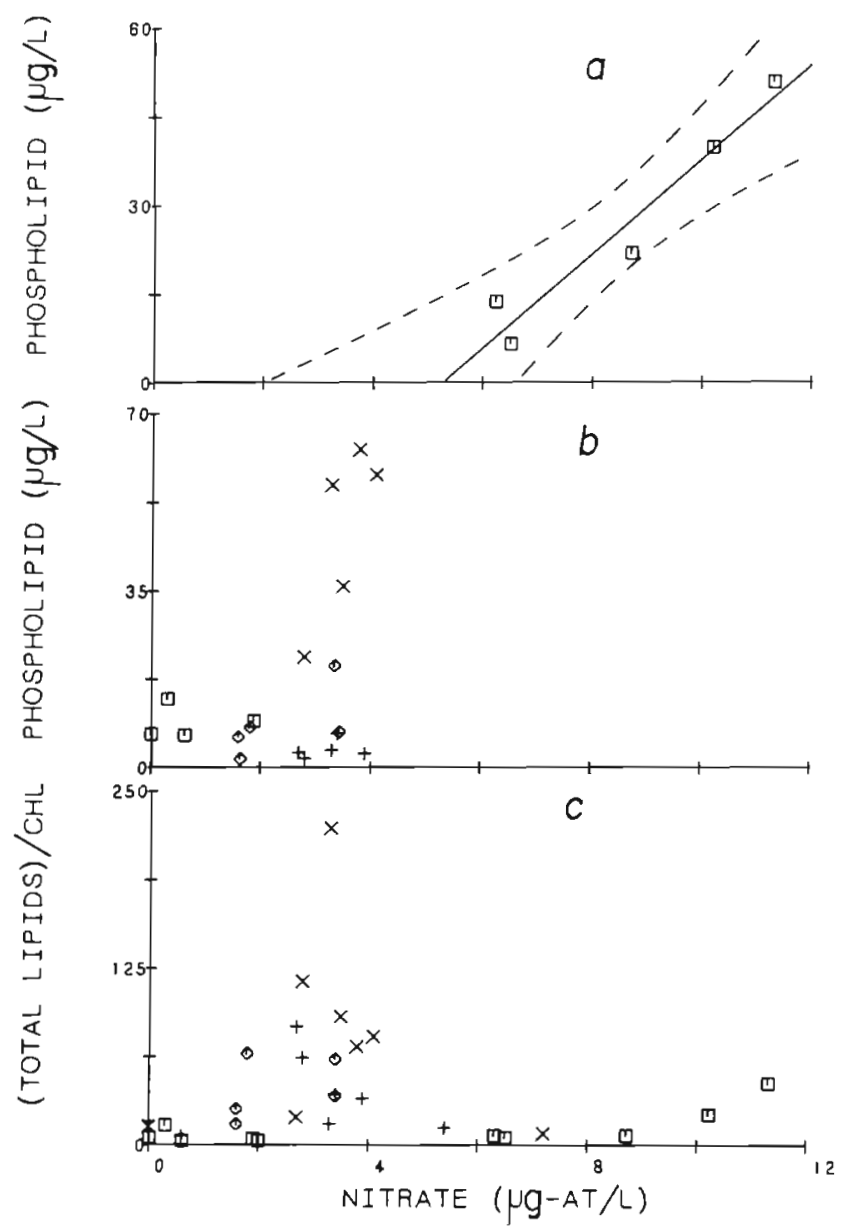

Fig. 7. Lipids versus dissolved inorganic nitrate concentrations for 1982 and 1984 spring bloom samples. Symbols as in Fig. 6. (a) Dissolved phospholipid concentrations from before 1982 chlorophyll a maximum. (b) Particulate phospholipid concentrations from after chlorophyll a maximum in both 1982 and 1984. (c) Ratio of total particulate lipid to chlorophyll a for all surface mixed layer samples from both spring blooms

column. Highest gross and net zooplankton growth efficiencies also occurred during this period (Conover \& Mayzaud 1984).

The pattern for PL was also similar to that in 1982. PL levels were higher after the chlorophyll maximum than before it, except that in 1984 the effect was much more marked (Fig. 5b). The higher levels of this membrane indicator class suggests greater numbers of organisms, possibly bacteria and/or microzooplankton. The lack of any increase in ST during this period would tend to favour bacteria, since bacterial cells contain few sterols. It should be noted that bacteria do not store TG either.

FFA and ALC (Fig. 5b, c) increased steadily through the bloom and afterwards and probably indicate the degree of lipid degradation in particulate matter. These hydrolysis products would be expected to 
increase as levels of detritus and faecal material increase.

\section{Lipids before and after the chlorophyll a maximum in 1982 and 1984}

Banse $(1974,1977)$ detailed the importance of grouping carbon, nitrogen and chlorophyll data into temporal or spatial assemblages before regression analysis. The most obvious point of reference for the grouping of data in this study is the maximum observed chlorophyll a concentration in the time series.

Data from the surface mixed layer in 1982 and 1984 were pooled to see if there was any significant difference between samples collected before the chlorophyll maximum in Bedford Basin and those collected after it. Data from the day of the chlorophyll maximum were not included because it is not known whether they are more representative of 'before' or 'after' (Table 3). The

Table 3. Particulate lipid and nutrient data from before and after the maximum measured chlorophyll a concentrations at the centre of Bedford Basin in 1982 and 1984. Data are from the top $10 \mathrm{~m}$ of the water column from 3 stations (Fig. 1); only data which were significantly different ( $95 \%$ confidence) are shown. All limits are $95 \%$ confidence intervals

\begin{tabular}{|c|c|c|}
\hline & Before $(n=10)$ & After $(n=22)$ \\
\hline $\begin{array}{c}\text { Dissolved inorganic } \\
\text { nitrate }\left(u g-\mathrm{at}^{-1}\right)\end{array}$ & $6.6 \pm 2.3$ & $2.6 \pm 0.6$ \\
\hline $\begin{array}{l}\text { Dissolved inorganic } \\
\text { phosphate }\left(\mu \mathrm{g} \text {-at } \mathrm{l}^{-1}\right)\end{array}$ & $1.1 \pm 0.3$ & $0.6 \pm 0.1$ \\
\hline $\begin{array}{l}\text { Total particulate } \\
\text { lipids }\left(\mu \mathrm{gl}^{-1}\right)\end{array}$ & $62 \pm 18$ & $116 \pm 27$ \\
\hline (Total lipids)/CHL & $15 \pm 10$ & $48 \pm 23$ \\
\hline $\begin{array}{l}\text { Particulate trigly- } \\
\text { ceride }\left(\mu \mathrm{gl} l^{-1}\right)\end{array}$ & $12 \pm 4$ & $30 \pm 10$ \\
\hline $\mathrm{TG} / \mathrm{CHL}$ & $2.5 \pm 1.9$ & $12 \pm 7$ \\
\hline $\begin{array}{l}\text { Particulate free fatty } \\
\text { acid }\left(\mu \mathrm{g}^{-1}\right)\end{array}$ & $8.2 \pm 3.4$ & $19 \pm 4$ \\
\hline FFA/CHL & $1.7 \pm 0.7$ & $8.3 \pm 3.5$ \\
\hline $\begin{array}{l}\text { Particulate phos- } \\
\text { pholipid }\left(\mu \mathrm{gl}^{-1}\right)\end{array}$ & $4.5 \pm 1.7$ & $16 \pm 9$ \\
\hline $\mathrm{PL} / \mathrm{CHL}$ & $0.9 \pm 0.5$ & $7.5 \pm 5.5$ \\
\hline
\end{tabular}

data were examined statistically using a t-test that did not require approximately equal variances (Ryan et al. 1976), because lipid data collected before the chlorophyll maximum were considerably less variable than data collected after it. Table 3 shows the concentrations and ratios that were significantly different.

It can be seen that concomitant with the significant differences in nutrients there were significant differences in lipids. There were generally much higher levels of lipids after the nutrients had become depleted. Using the interpretations of lipid class data discussed in Parrish (1986), Table 3 indicates that there were more storage products, more degradation, and more membrane material after the chlorophyll maximum. The increase in variability in the concentrations of these indicator classes undoubtedly reflects changes in levels of the various components of particulate matter: algae, detritus, microzooplankton and faecal material.

Several classes showed no significant difference between before and after the chlorophyll maximum; 2 examples of such data distributions are shown in Fig. $6 \mathrm{a}, \mathrm{b}$. For comparison, Fig. $6 \mathrm{c}$ shows a situation where there was a significant difference.

Dissolved HC (Fig. 6a) bears no relation to the chlorophyll a distribution, although there does appear to be generally less $\mathrm{HC}$ from the middle of the sampling periods onwards, presumably as a result of the decreased use of fuel oils with the approach of summer (Gordon et al. 1978). Samples from Halifax Harbour were generally higher in $\mathrm{HC}$ than those from the other stations (Fig. 1). This is to be expected because the station is adjacent to a large container pier, and there is considerable shipping traffic in the area.

For both blooms and all 3 depths, highest particulate ST concentrations occurred within 2 wk of the chlorophyll maximum (Fig. 6b). ST consistently showed a sharp increase on the day of the chlorophyll maximum. This result, coupled with the linear relation between sterols and growth rate in turbidostat cultures (Parrish \& Wangersky 1987), suggests that where chlorophyll $a$ values are high, enhanced particulate sterol levels can also be used as an indicator of healthy, actively dividing cells. The second ST peak observed in 1982 (Fig. 6b) occurred when chlorophyll levels were low (Fig. 2a), but PL levels were high (Fig. 3a). This combination would suggest the presence of a large microzooplankton population.

\section{Lipids and inorganic nitrate during 1982 and 1984 blooms}

One of the most dramatic aspects of seawater chemistry during a spring bloom is the precipitous drop in nitrate concentrations to levels below the detection limit. That this should significantly affect algal physiology and metabolism is without question. How this in turn affects dissolved and particulate lipid class concentrations has been a primary concern of this discussion.

Although there are clear and coincident differences in lipids and nutrients before and after the chlorophyll maximum (Table 3), a causal relation does not necessarily exist. A stronger test of such a relation is a regression between nitrate and concentrations of a 
lipid class that could be expected to be directly related to nutrient levels. PL is obviously the best contender for such a relation

The 2 significant linear regressions obtained with PL are shown in Fig. $7 \mathrm{a}, \mathrm{b}$. The relation between dissolved PL and nitrate before the chlorophyll maximum is significant at the $99 \%$ level, but after the 1982 chlorophyll maximum it was very different: the correlation was not significant at the $95 \%$ confidence level, and the sign for the Pearson product moment correlation coefficient was negative. A regression involving all the pairs of dissolved PL and nitrate data from after the chlorophyll maximum in both 1982 and 1984 produces a correlation coefficient that is again negative. This suggests that the factors controlling dissolved PL concentrations before chlorophyll maxima are different from those controlling the concentrations afterwards.

Fig. 7a indicates that dissolved phospholipids may be assimilated for the same reasons that dissolved inorganic nutrients are. Phospholipids are thought to be taken up by algae in order to provide a source of phosphorus (Langowska 1982, Admiraal \& Werner 1983). The action of cell-surface phosphatases would make the phosphate available to the algae, and the remainder of the phospholipid molecule would presumably re-enter the dissolved fraction of seawater. This new lipid material entering seawater is likely to be composed primarily of partial glycerides, especially diglycerides. However, it is the monoglycerides that might be expected to accumulate in the environment because lipases tend to act more efficiently on diglycerides than on monoglycerides (Gurr \& James 1980). The high levels of dissolved AMPL found in surface waters (Delmas et al. 1984, Parrish 1986) could indicate that this does occur. The $R_{\mathrm{f}}$ value of monoglycerides is identical to that of AMPL in the solvent systems used for the Chromarod TLC separations (Parrish 1986). However, as indicated in Table 1 and in the choice of name for this class, the identity of the constituents of acetone-mobile polar lipids is uncertain. This could only be resolved by a detailed analysis of dissolved polar lipids at the molecular level by GC and HPLC.

The linear relation with particulate PL (Fig. $7 \mathrm{~b}$ ) is significant only at the $95 \%$ level, though clearly 2 linear regressions or a non-linear regression would give a better fit. Fig. $7 \mathrm{~b}$ suggests that membrane material may be rapidly synthesized only beyond a certain threshold of nutrient levels in the water column. Very high PL concentrations occurred only beyond $2 \mu \mathrm{g}$-at $\mathrm{l}^{-1}$ of nitrate. Such a threshold relation could be important for the synthesis of other particulate lipid classes: Fig. $7 \mathrm{C}$ suggests that there is a narrow range of nitrate concentrations over which lipid synthesis is maximised. For both blooms and all 3 sampling stations, the highest values per unit chlorophyll a occurred between 2 and $4 \mu \mathrm{g}$-at $\mathrm{l}^{-1}$. Beyond $4 \mu \mathrm{g}$-at $\mathrm{l}^{-1}$ it is likely that the algal cells favoured the synthesis of biochemical classes other than lipids.

\section{CONCLUSION}

There were significant variations in the concentrations of dissolved and particulate lipid classes during spring phytoplankton blooms in Bedford Basin. There was a greater variability in lipid class concentrations after the maximum observed chlorophyll a value during the bloom; dissolved lipid class concentrations were nearly always more variable than those of the same class in the particulate fraction.

Dissolved and particulate measurements of the same class were poorly correlated. This indicates that different processes were controlling the concentrations of the lipid classes in the dissolved and particulate fractions. Particulate lipid class concentrations were almost invariably high during periods when chlorophyll levels were at their highest. This is undoubtedly the result of a close association between particulate lipid classes and phytoplankton productivity. By contrast, several dissolved lipid classes were at their lowest levels at that time. This could be the result of heterotrophic assimilation of dissolved lipid classes.

Several dissolved and particulate acyl lipid classes show maximal concentrations after the chlorophyll maximum, indicating that the supply of high-energy compounds far exceeds demand by heterotrophs at that time. The concentrations of hydrocarbons are for the most part unrelated to chlorophyll or nutrient levels, suggesting an anthropogenic contribution.

Acknowledgements. This research was supported by grants from the Natural Sciences and Engineering Research Council to P. J. Wangersky and R. G. Ackman. An Izaak Walton Killam Memorial Scholarship supported C. C. Parrish. M. R. Lewis and S. Roy kindly provided nutrient and fluorometric chlorophyll a data, together with information on in situ fluorescence and species composition. Drs. Ackman, Roy, and Wangersky provided useful comments on previous versions of this text.

\section{LITERATURE CITED}

Admiraal, W., Wemer, D. (1983). Utilization of limiting concentrations of ortho-phosphate and production of extracellular organic phosphates in cultures of marine diatoms. J. Plankton Res. 5: 495-513

Banse, K. (1974). On the interpretation of data for the carbonto-nitrogen ratio of phytoplankton. Limnol. Oceanogr. 19: $695-699$

Banse, K. (1977). Determining the carbon-to-chlorophyll ratio of natural phytoplankton. Mar Biol. 41: 199-212

Conover, R. J., Mayzaud, P. (1984). Utilization of phytoplank- 
ton by zooplankton during the spring bloom in a Nova Scotia inlet. Can. J. Fish. Aquat. Sci. 41: 232-244

Conover, S. A. M. (1975). Nitrogen utilisation during spring blooms of marine phytoplankton in Bedford Basin, Nova Scotia, Canada. Mar. Biol. 32: 247-261

Delmas, R. P., Parrish, C. C., Ackman, R. G. (1984). Determination of lipid class concentrations in seawater by thinlayer chromatography with flame ionization detection. Analyt. Chem. 56: 1272-1277

Environment Carada (1984). Monthly meteorological summary, February-April, 1984. Halifax - Dartmouth, N.S. (Shearwater A.). Environment Canada, Atmospheric Environment, Ottawa

Fraser, A. J., Tocher, D. R., Sargent, J. R. (1985). Thin-layer chromatography - flame ionization detection and the quantitation of marine neutral lipids and phospholipids. J. exp. mar. Biol. Ecol. 88: 91-99

Gordon, D. C., Keizer, P. D., Dale, J. (1978). Temporal variations and probable origins of hydrocarbons in the water column of Bedford Basin, Nova Scotia. Estuar. coast. mar. Sci. 7: 243-256

Gurr, M. I., James, A. T. (1980). Lipid biochemistry: an introduction. 3rd edn. Chapman and Hall, London

Kattner, G., Gercken, G., Eberlein, K. (1983a). Development of lipids during a spring plankton bloom in the northern North Sea. I. Particulate fatty acids. Mar. Chem. 14: $149-162$

Kattner, G., Gercken, G., Hammer, K. D. (1983b). Development of lipids during a spring plankton bloom in the northern North Sea. II. Dissolved lipids and fatty acids. Mar. Chem. 14: 163-173

Langowska, I. (1982). Utilization of organic phosphates by selected bacteria and algae. Water Res. 16: 161-167

Lewis, M. R., Horne, E. P. W., Cullen, J. J., Oakey, N. S., Platt, T. (1984). Turbulent motions may control phytoplankton photosynthesis in the upper ocean. Nature, Lond. 311: 49-50

Morris, R. J., McCartney, M. J., Robinson, G. A. (1983). Studies of a spring phytoplankton bloom in an enclosed experimental ecosystem. I. Biochemical changes in relation to the nutrient chemistry of water. J. exp. mar. Biol. Ecol. 70: 249-262

Parrish, C. C. (1986). Dissolved and particulate lipid classes in the aquatic environment. Ph. D. dissertation, Dalhousie University

Parrish, C. C., Ackman, R. G. (1983). Chromarod separations for the analysis of marine lipid classes by latroscan thinlayer chromatography - flame ionization detection. J. Chromatogr. 262: 103-112

Parrish, C. C., Ackman, R. G. (1985). Calibration of the Iatroscan-Chromarod system for marine lipid class analyses. Lipids 20: 521-530

Parrish, C. C., Wangersky, P. J. (1987). Particulate and dissolved lipid classes in cultures of Phaeodactylum tricornutum grown in cage culture turbidostats with a range of nitrogen supply rates. Mar. Ecol. Prog. Ser. 35: 119-128

Platt, T., Irwin, B., Subba Rao, D. V. (1973). Primary productivity and nutrient measurements on the spring phytoplankton bloom in Bedford Basin, 1971. Fish. Res. Bd Can. Tech. Rep. No. 423, p. 1-45

Roy, S. (1986). Marine chloropigments: chromatographic measurement in phytoplankton and transformations in algal cultures and a spring bloom event in a marine bay. Ph. D. dissertation, Dalhousie University

Ryan, T A., Joiner, B. L., Ryan, B. F. (1976). Minitab student handbook. Duxbury Press, Massachusetts

Water Survey of Canada (1985). Surface water data, Atlantic provinces. Inland Waters Directorate, Water Resources Branch, Ottawa

This article was submitted to the editor; it was accepted for printing on November 5, 1986 